РУДАКОВА Екатерина Константиновна - кандидат политических наук, доцент кафедры межжународных отношений и политологии, старший научный сотрудник Нижегородского государственного лингвистического университета им. Н.А. Добролюбова (603155, Россия, г. Нижний Новгород, ул. Минина, 31a; kafedra_mo_nglu@таil.ru)

ШУМАКОВА Ольга Николаевна - кандидат философских наук, профессор кафедры философии и эстетики Нижегородской государственной консерватории им. М.И. Глинки (603950, Россия, г. Нижний Новгород, ул. Пискунова, 40)

\title{
ПРАВОВЫЕ И ЭТИЧЕСКИЕ ПРОБЛЕМЫ ИСПОЛЬЗОВАНИЯ ВСПОМОГАТЕЛЬНЫХ РЕПРОДУКТИВНЫХ ТЕХНОЛОГИЙ В ЗАРУБЕЖНОМ ДИСКУРСЕ В КОНТЕКСТЕ ДЕМОГРАФИЧЕСКОЙ БЕЗОПАСНОСТИ РОССИИ
}

\begin{abstract}
Аннотация. В статье рассматривается зарубежный дискурс в отношении правовых, этических, социальных и демографических последствий применения новых медицинских технологий в репродуктивной сфере в контексте обеспечения демографической безопасности государства. Авторы приходят к заключению, что в российском законодательстве необходимы ограничения в отношении некоторых видов репродуктивных технологий, противоречащих нормам международного и национального права, угрожающих психическому и физическому здоровью будущих поколений. Исследование показало, что в большинстве западных стран новые репродуктивные технологии, такие как суррогатное материнство, донорство яйцеклеток, экстракорпоральное оплодотворение, уже получили существенные законодательные ограничения в силу малой изученности последствий применения данных технологий для здоровья матери и ребенка, а также по причине этических и религиозных традиций в обществе.

Ключевые слова: демографическая безопасность, вспомогательные репродуктивные технологии, экстракорпоральное оплодотворение, суррогатное материнство, этика, мораль, права человека
\end{abstract}

$\Pi$ роблема применения новых вспомогательных репродуктивных технологий в медицине (экстракорпоральное оплодотворение, суррогатное материнство, донорство и криоконсервация репродуктивных органов и эмбрионов, митохондриальное замещение и т.д.) является малоизученным аспектом обеспечения демографической безопасности. Эта тематика не может рассматриваться исключительно как медицинская, поскольку обеспечение стабильного демографического развития страны как составляющей системы национальной безопасности является прерогативой государства, его стратегическим национальным приоритетом ${ }^{1}$.

Анализ зарубежных источников по данной проблеме показал, что в мире идет серьезная научная полемика по вопросам правовых, социальных, демографических последствий применения данных технологий, в некоторых странах введены законодательные ограничения и запреты на отдельные виды репродуктивных технологий по этическим и нравственным соображениям, а также вследствие недостаточной изученности вопроса.

В России направление вспомогательных репродуктивных услуг является одним из самых доступных в мире. В первую очередь это связано с упрощенным законодательством и отсутствием жестких правовых ограничений. Причиной

1 Указ Президента РФ от 31.12.2015 № 683 «О стратегии национальной безопасности Российской Федерации». Доступ: http://www.consultant.ru/document/cons_doc_LAW_191669/ (проверено 14.03.2020). 
является и низкая рождаемость, и такой ее демографический показатель, как фертильность. В России проблема фертильности населения приобретает катастрофические масштабы. По данным медицинской статистики, частота бесплодия в России составляет 17-20\%, в то время как ВОЗ считает угрозой демографической безопасности государства потолок в 15\% [Сосновская 2017].

В отношении вспомогательных репродуктивных технологий в российском законодательстве есть серьезные понятийные разногласия. Важнейшей функцией государства является «сохранение и восполнение здоровья населения», которое, согласно российскому законодательству, трактуется как состояние «физического здоровья, психического и социального благополучия человека, при котором отсутствуют заболевания, а также расстройства функций органов и систем организма»1. То есть, вспомогательные репродуктивные технологии никак не могут трактоваться как «методы лечения» и достижение «здорового состояния организма», поскольку сами врачи определяют бесплодие не как болезнь, а как «дисфункциональное неизлечимое состояние», при котором восстановление здоровых репродуктивных функций организма, зачатие и рождение детей невозможны. Но почему-то и в федеральном законодательстве, и в медицинской практике вспомогательные репродуктивные технологии повсеместно определяются как метод лечения бесплодия 2 .

Может показаться, что в борьбе за рождаемость в России именно вспомогательные репродуктивные технологии должны стать действенным методом преодоления проблемы низкой фертильности, т.е. неспособности зачать и выносить ребенка естественным путем. Однако, по мнению самих врачей, несмотря на внешнюю простоту выполнения вспомогательных репродуктивных процедур, применение их не всегда обоснованно и целесообразно, остается очень много неизученных вопросов, частота наступления беременности не превышает $39 \%$, а изучению последствий применения данных технологий для матери и ребенка посвящено необоснованно мало специализированных работ [Самойлова 2009: 5].

За рубежом данные виды технологий находятся под строгим законодательным контролем, что связано с множеством противоречий, возникающих в ходе их применения. Рассмотрим основные, на которые обращают внимание зарубежные специалисты.

1. Нарушение прав детей в призме международного права сопряжено с такими неотъемлемыми правами, как право на здоровье в дородовый и послеродовый период, охрана здоровья, упразднение традиционной практики, отрицательно влияющей на здоровье детей, право знать своих родителей и право на их заботу, недопущение торговли детьми или их контрабанды в любых целях и в любой форме, право на честь и достоинство, право на защиту от любых форм эксплуатации, особенно женщин и детей ${ }^{3}$.

1 Концепция демографической политики Российской Федерации на период до 2025 года. Утв. указом Президента РФ от 09.10.2007 № 1351. Доступ: http://www.demoscope.ru/weekly/knigi/ koncepciya/koncepciya25.html (проверено 14.03.2020).

2 Федеральный закон «Об основах охраны здоровья граждан в РФ» от 21.11.2011 № 323-Ф3 (ред. от 29.05.2019). Ст. 55 Применение вспомогательных репродуктивных технологий. Доступ: http://www.consultant.ru/document/cons_doc_LAW_121895/3b0e0cbbd6flb1a07c0b0b3d4df406a2ecf 108a1/ (проверено 14.03.2020).

3 Конвенция о правах ребенка. Одобрена Генеральной Ассамблеей ООН 20.11.1989. Доступ: http://www.consultant.ru/cons/cgi/online.cgi? req $=$ doc\&base $=$ LAW $\& n=9959 \&$ fld $=134 \& d s t=100018,0$ $\& \mathrm{rnd}=0.4326503661510994 \# 06785331732098874$; Протокол о предупреждении и пресечении торговли людьми, особенно женщинами и детьми. Принят Резолюцией 55/25 Генеральной Ассамблеи ООН от 15.11.2000. Доступ: https://www.un.org/ru/documents/decl_conv/conventions/ protocoll.shtml; Всеобщая декларация прав человека. Принята Резолюцией 217 А (III) Генеральной Ассамблеи ООН от 10.12.1948). Доступ: https://www.un.org/ru/documents/decl_conv/ declarations/declhr.shtml (проверено 14.03.2020). 
Данному аспекту посвящено немало зарубежных исследований, в России эта тема практически не поднимается. Так, в научной статье «Узаконить суррогатное материнство - значит нарушить права детей» профессор кафедры здравоохранения и прав человека университета Монаш (Австралия) Лиза Бишоп и директор Центра здравоохранения и прав человека им. Майкла Кирби (Австралия) Бэбе Лофф доказывают, что единственной стороной, которая обладает неотъемлемыми правами в коммерческом суррогатном материнстве, является ребенок, который рожден в результате заключения коммерческого соглашения. Ученые подчеркивают, что, рассуждая о новых медицинских технологиях, никто не говорит о правах детей, что особенно странно, потому что дискуссия вокруг коммерческого суррогатного материнства строится в основном на языке прав человека. Каждый человек имеет право быть рожденным естественным путем, от родных матери и отца, но данное право практически игнорируется в дискуссиях о суррогатном материнстве.

Важным положением статьи является утверждение, что «желание иметь детей не есть право», «в международном законодательстве признанным является право на создание семьи, право на использование результатов научного прогресса, но право на создание ребенка искусственным путем не есть право в его подлинном смысле, это лишь претензия на право, желание, что само по себе не создает правоотношений». «Так, - пишут австралийские эксперты, - отсутствие дееспособности однополых союзов произвести на свет ребенка не дает им права на ребенка, тем более прав на контрактные договоренности в отношении его приобретения, поскольку на правовом языке наши желания - не есть наши права» 1 .

Действительно, тема прав детей почти не поднимается в дискуссиях по вопросу применения вспомогательных репродуктивных технологий, хотя закрепленное в Конвенции о правах ребенка положение гарантирует не только право на достоинство, но также право на защиту от продажи или торговли людьми, регистрацию рождения и право знать своих родителей. «Ребенок не может быть приобретен в результате коммерческой сделки и быть купленным, как щенок. Это попрание человеческого достоинства. Желания взрослых не могут ставиться выше прав человека», - делают вывод австралийские эксперты ${ }^{2}$. Практика показывает, что дети, рожденные, например, от экстракорпорального оплодотворения и суррогатного материнства, глубоко интересуются своим происхождением и чувствуют себя отличными от детей, рожденных естественным путем.

Немецкие ученые отстаивают необходимость запрета всех форм суррогатного материнства и экстракорпорального оплодотворения. Физиолог, медицинский журналист Мириам Фанк в своей статье «Суррогатная мать» пишет: «Договорная основа и контракт с суррогатной матерью являются незаконными, так как ни один человек не может быть частью договора купли-продажи. Именно поэтому по этическим и моральным соображениям суррогатное материнство в Германии запрещено» 3 .

Отметим, что сегодня в большинстве стран Европы суррогатное материнство на коммерческой основе уже запрещено, и это строго охраняется законом. Совет Европы отказался от суррогатного материнства в 2016 г. К законодатель-

1 Bishop L., Loff B. Making surrogacy legal would violate children's rights. - The Conversation. 20.08.2014. URL: https://theconversation.com/making-surrogacy-legal-would-violate-childrensrights-30716 (accessed 13.03.2020).

2 Ibid.

3 Funk M. Leihmutter. - Letzte Aktualisierung. 28.04.2017. Доступ: https://www.9monate.de/ kinderwunsch-familienplanung/unerfuellter-kinderwunsch/leihmutter-id94149.html (проверено 13.03.2020). 
ным запрету или ограничениям пришли Франция, Канада, Норвегия, Швеция, Австрия, Австралия, Италия, Испания, Ирландия, Индия, которая до недавнего времени являлась центром международного «суррогатного туризма». В Германии, Италии и Франции суррогатное материнство карается тюремным заключением, это связано как с религиозными и этическими традициями данных стран, не приемлющими современные репродуктивные технологии, так и с негативными социальными и демографическими последствиями суррогатного материнства, которые приводят к эксплуатации и коммерциализации репродуктивной сферы, нарушению прав в отношении торговли людьми. В Германии, Франции, Италии, Австрии, Дании, Швейцарии запрещена реклама суррогатного материнства, а также поиск суррогатной матери по объявлению. Список стран, где разрешено суррогатное материнство, даже на коммерческой основе, не так уж и велик - некоторые штаты США, Украина, Россия, Армения, Грузия, Киргизия, Белоруссия, Латвия, Чехия.

Профессор Мельбурнского университета, эксперт в области правовых вопросов применения репродуктивных технологий Шейла Джефрис в своей статье «Отказ от коммерческого материнства как еще одной формы торговли людьми» рассматривает риски, связанные с правами ребенка. В промежутке между вынашиванием и рождением ребенка происходят самые разнообразные события смерть или инвалидность потенциальных родителей, развод родителей, ссора с суррогатной матерью, вынашивающей ребенка, или просто отказ от ребенка. Это не отдельные случаи, а реальные риски, и едва ли современное общество будет в состоянии заставить нести ответственность за ребенка, если этого желания больше нет. Истории, когда дети могут родиться больными (как, например, тайский младенец Гамми, от которого отказались его новые австралийские родители, забрав только здоровую сестру-близнеца), нередки.

Шейла Джефрис полагает, что «суррогатное материнство является очень прибыльным направлением индустрии репродуктивных технологий, которая рассматривает ребенка как товар, а женщину, вынашивающую ребенка, как торгующую своим телом, которая подвергается эксплуатации, в данном случае через свои репродуктивные органы. Эта проблема замалчивается, а ведь есть страны, в которых существуют целые рабские лагеря, в которых вынашиваются дети и увозятся на другие континенты. При этом детей могут бросить, отвергнуть, оставить. Обсуждение суррогатного материнства не может строиться только вокруг прав покупателей, права ребенка должны исследоваться в первую очередь»1.

2. Трансформация места материнства в обществе. Эксплуатация репродуктивных возможностей женщин и мужчин.

Профессор кафедры биоэтики и философии университета Дэлхаузи (Канада) Франсуаза Бейлис и исследователь университета Саскачевана (Канада) Франсуаза Бейли в своем исследовании пишут, что женщины, которые вынашивают пусть и не своего ребенка, но которые создавали его в течение нескольких месяцев из своей плоти и крови, называются ненастоящими матерями, тем не менее они весьма страдают от отнятия детей. Данный подход канадские исследователи считают циничным и противоречащим этике их страны, поскольку женское тело - это не фабрика, а дети - не продукты. «При таком подходе мы рискуем потерять образ человечности. Деторождение сегодня может перестать быть связанным с материнством. Случай, когда японский бизнесмен приобрел 13 детей от суррогатных матерей, чтобы иметь наследников для своего бизнеса, яркий тому пример, когда мужчины могут иметь детей и больше не связывать

\footnotetext{
${ }^{1}$ Jeffreys Sh. Reject commercial surrogacy as another form of human trafficking. - The Conversation. 11.08.2014. URL: https://theconversation.com/reject-commercial-surrogacy-as-another-form-ofhuman-trafficking-30314 (accessed 13.03.2020).
} 
себя обязательствами с женщиной». Действительно, эти дети могут быть приобретены для жестокого обращения или насилия, торговли органами, сексуальной эксплуатации, и рядом с ними не будет матери, которая будет заинтересована и обязана их защищать. Подобные прецеденты в мире, к сожалению, уже существуют, и поэтому здесь необходимы жесткие законодательные ограничения 1 .

Канадские ученые отмечают, что существуют веские этические причины для запрещения торговли репродуктивными возможностями женщин и мужчин и эксплуатации детей в коммерческих целях. Среди этих причин - необходимость предотвратить превращение человеческого тела в товар. Именно поэтому федеральное правительство Канады в 2004 г. ввело уголовный запрет на оплату суррогатного материнства, а также человеческой спермы и яйцеклеток. В Канаде запрещено оплачивать услуги суррогатной матери или приобретать человеческие гаметы-сперму и яйцеклетки, хотя некоторые либеральные парламентарии хотят это изменить ${ }^{2}$.

Специалист в области прав человека в Индии Шармила Рудраппа в своей статье «Индия запретила коммерческое суррогатное материнство» пишет, что правительство Индии пересматривает репродуктивное законодательство. С 2012 г. однополым парам запрещено использовать услуги суррогатных матерей. С марта 2017 г. индийское правительство распространило законодательный запрет на все виды коммерческого суррогатного материнства. Теперь разрешено только так называемое «альтруистическое суррогатное материнство», когда женщина - член семьи по взаимному согласию вынашивает ребенка для бездетной гетеросексуальной индийской пары без оплаты труда ${ }^{3}$.

\section{3. Право на информацию.}

Многие из тех, кто соглашается на использование современных медицинских технологий, не в полной мере ознакомлены с научными данными о последствиях их применения. Сегодня даже врачи не обладают полной информацией о том, как влияют методы суррогатного материнства или экстракорпорального оплодотворения на ребенка и мать. Но есть доказательства, что фаза зачатия и внутриутробного развития является важнейшей в дальнейшем развитии ребенка, а материнское поведение оказывает первостепенное воздействие на развивающийся плод и здоровье новорожденных. Недавнее исследование показало, что дети, рожденные в результате суррогатного материнства, имеют больше проблем с поведением и адаптацией в детстве, чем те, кто родился естественным путем. Контакт тела родной матери с ребенком в утробе очень важен, так же как и звук ее голоса, сердцебиение и прикосновения ее рук к животу» 4 .

Акушер-гинеколог центра женского здоровья Татьяна Строкова пишет, что в России практически нет статистики последствий проведения экстракорпорального оплодотворения для здоровья матери и ребенка. Но есть данные, которые свидетельствуют, что данная процедура небезопасна. «Перед проведением ЭКО проводится мощная гормонотерапия с целью появления как можно большего количества яйцеклеток, данная процедура не может проходить без

\footnotetext{
1 Ibid.

2 Baylis F., Kattapan A. Paying surrogates, sperm and egg donors goes against Canadian values. - The Conversation. 2.04.2018. URL: https://theconversation.com/paying-surrogates-sperm-and-egg-donorsgoes-against-canadian-values-94197 (accessed 13.03.2020).

3 Rudrappa Sh. India outlawed commercial surrogacy - clinics are finding loopholes. - The Conversation. 23.10.2017. URL: https://theconversation.com/india-outlawed-commercial-surrogacyclinics-are-finding-loopholes-81784 (accessed 13.03.2020).

4 Baines S. Surrogacy: what you need to know about having a baby. - The Conversation. 19.06.2018. URL: https://theconversation.com/surrogacy-what-you-need-to-know-about-having-a-baby-96147 (accessed 13.03.2020).
} 
последствий. Частый результат гиперстимуляции - кисты яичников, миоматозные узлы, ранний климакс, износ репродуктивной системы и фолликулярного запаса, проблемы с внутренними органами, очень часто - с печенью и щитовидной железой. ЭКО - работа на результат любой ценой, и многие последствия данной процедуры непредсказуемы». Женщины также должны понимать, что «ЭКО - это эксперимент на людях, и цена эксперимента - человеческая жизнь. Большинство клиник сегодня работают на результат за счет оплодотворения как можно большего числа яйцеклеток, потому что шанс оплодотворения лишь одной яйцеклетки (in vitro) чрезвычайно невелик. Так появляется проблема “лишних эмбрионов”. Два или три эмбриона подсаживают в полость матки, потом лишних, даже прижившихся, редуцируют. Редукция - по сути, убийство эмбрионов - происходит с помощью тонкой иглы, которую вводят будущему ребенку в сердце, и оно перестает биться. Затем эмбрион рассасывается, но случается, что редукция провоцирует выкидыш, и погибают другие эмбрионы, которых пациентка хотела оставить» ${ }^{1}$. Не случайно метод ЭКО во многих странах считается этически недопустимым и осуждается всеми конфессиями, в т.ч. и в России.

Часто желание бесплодных пар родить ребенка любой ценой бывает настолько сильным, что ни проблемы со здоровьем, ни возраст их не останавливают. «У одной моей пациентка в анамнезе было 15 (!) протоколов ЭКО. В результате она все же родила ребенка с тяжелейшей формой ДЦП». Мианна Лотц в своей статье описывает случай с 57-летней мисс Толлефсон, которая в свое время родила ребенка посредством экстракорпорального оплодотворения и сегодня является активистом за введение возрастных ограничений, призывает правительства стран задуматься о возрастном лимите на доступ к вспомогательным репродуктивным технологиям и их последствиях. Женщина не жалеет, что родила дочь, но поняла, что у детей, рожденных от престарелых родителей, есть серьезные риски остаться одинокими. Ребенок, безусловно, не имел возможность выбора, и его об этом никто не спросил ${ }^{2}$.

Многогранной иллюстрацией к данной теме является вышедшая в Великобритании книга «Истоки любви: реальности и этика репродуктивного туризма». В ней на примере калейдоскопа жизненных историй показывается не только боль бездетных пар, но и оборотная сторона нелегального суррогатного материнства и абортов, говорится о том, как люди, врачи, становятся втянутыми в эту индустрию и о тяжелых моральных последствиях. О том, что тысячи эмбрионов становятся контрафактным товаром по всему миру, все больше импортируются, используются в качестве стволовых клеток - как чудодейственное лекарство в косметологии и медицине, а коррумпированные чиновники закрывают на это глаза. Это и истории молодых девушек, бедных и необразованных, которые под давлением своих мужей, родителей идут на этот шаг и становятся суррогатными матерями. «Нищета женщин не оправдывает нарушение прав детей. Скорее необходимо решать проблемы, связанные с расширением возможностей и образования женщин». Об этом же пишут и немецкие авторы: «Беременность - это интимный, эмоциональный и личный процесс, который не должен подвергаться рыночной логике. В этом проявляется эксплу-

\footnotetext{
1 Симанкова Е. ЭКО: не всем хватит жизни, чтобы расплатиться. Какие последствия для женского здоровья может иметь ЭКО и почему в России нет статистики его последствий? Милосердие.RU. 28.11.2017. Доступ: https://www.miloserdie.ru/article/eko-ne-vsem-hvatit-zhiznichtoby-rasplatitsya/ (проверено 14.03.2020).

2 Lotz M. IVF treatment for older women: is age the greatest concern? - The Conversation 16.10.2012. URL: https://theconversation.com/ivf-treatment-for-older-women-is-age-the-greatestconcern-4141 (accessed 13.03.2020).
} 
атация женщины, которая проявляется, в частности, в том, что из-за плохого финансового положения на женщину оказывают давление родители, агентства, клиники, которые благодаря навязчивой рекламе используют финансовую неустойчивость женщины в своих интересах»1 [Siegl 2019].

4. Этический предел медицинских технологий.

Правовая проблема новых медицинских технологий связана с тем, что мы нарушаем право ребенка родиться на свет естественным путем. Конечно, современное сопровождение беременности и родовспоможение уже есть частичное вмешательство в естественный процесс рождения, и многие дети не появились бы на свет без достижений медицины. Но должна быть определена граница экспериментов, и едва ли кто-то захотел бы стать жертвой медицинских опытов еще до появления на свет.

Исследователь правового регулирования новых медицинских технологий Роза Кастро пишет об этом в своей работе «Генетическая модификация - это следующий рубеж в репродуктивных технологиях?» Она описывает случай рождения в Великобритании в 2016 г. первого ребенка методом так называемой митохондриальной замены, когда ребенок был рожден от ДНК трех человек: яйцеклетки матери, здорового донора и сперматозоида отца, для того чтобы исключить передачу от матери опасного заболевания синдрома Ли. Данный метод не регулируется никакими международно-правовыми нормами, единственная страна, которая делает подобное, это Великобритания. Роза Кастро говорит, что многие правовые вопросы использования медицинских технологий сегодня остаются без ответа. США, где запрещено рассматривать вопрос о замене митохондрий, выразили серьезную озабоченность в связи с применением данного метода в Великобритании, поскольку замена митохондрий приводит к изменению зародыша и по женской линии передается будушим поколениям. В свою очередь Мексика, Китай и Украина заявили об апробации подобных технологий. Вопрос у всех на устах: «Что делать, если дети, рожденные в результате этих методов, будут страдать от неизвестных неблагоприятных последствий? Как насчет этичности утилизации эмбрионов?» Автор статьи полагает, что правительствам следует рассмотреть этические и безопасные для своих стран демографические последствия выбора репродуктивных технологий ${ }^{2}$.

Очевидно, что задача российского государства - это не поошрение развития вспомогательных репродуктивных технологий, а борьба с заболеваниями, вызывающими низкую фертильность мужчин и женщин в России. Так, доктор медицинских наук И.С. Савельева пишет, что одной из главных причин низкой фертильности женщин в России, наравне с алкоголизмом, курением, наркоманией, наследственными генетическими заболеваниями, является массовое прерывание первой беременности. Установлена высокая частота осложнений после искусственного прерывания первой беременности у девушек-подростков - 14,0\%; структура осложнений представлена воспалительными заболеваниями репродуктивных органов $-50,0 \%$. Анализ клинического течения беременности у повторно беременных показал, что искусственный аборт в анамнезе при прочих равных условиях является тем фактором, который определяет или усугубляет патологическое течение беременности и родов у первородящих женщин. Установлен высокий риск развития угрозы прерывания беременности $-69,6 \%$,

1 Skene L. Origins of love: the reality and ethics of reproductive tourism. - The Conversation. 18.10.2012. URL: https://theconversation.com/origins-of-love-the-reality-and-ethics-of-reproductivetourism-9815 (accessed 13.03.2020).

2 Kastro R. The next frontier in reproductive tourism? Genetic modification. - The Conversation. 18.11.2016. URL: https://theconversation.com/the-next-frontier-in-reproductive-tourism-geneticmodification-67132 (accessed 13.03.2020). 
поздних форм гестоза - 18,9\%, хронической плацентарной недостаточности $25,0 \%$ и внутриутробной задержки развития плода - 7,4\% [Савельева 2004].

Таким образом, несмотря на то что новые вспомогательные репродуктивные технологии уже применяются в России, стоит задуматься об их скорейшем законодательном ограничении с учетом зарубежного опыта, а также нравственных и этических традиций народов России, основанных на уважении неотъемлемых прав личности на жизнь и здоровье.

\section{Список литературы}

Савельева И.С. 2004. Репродуктивное здоровье и репродуктивное поведение современной молодежи: перспективы и пути оптимизации: автореф. дис. ... Д.мед.н. 14.00.01. M. 44 c.

Самойлова А.В. 2009. Морфофункциональные аспекты повышения эффективности экстракорпорального оплодотворения: дис. ... Д.мед.н. 02.00.25. Саранск. 36 с.

Сосновская Т.С. 2017. Бесплодие как социально-демографическая проблема России. - Научное сообщество студентов. Междисциплинарные исследования. № 21(32). Доступ: https://sibac.info/archive/meghdis/21\%2832\%29.pdf (проверено 13.03.2020).

Siegl V. 2019. Analyse: Leihmutterschaft in der Ukraine: Aufstieg - und Fall? - eines lukrativen internationalen Marktes. - Bundeszentrale fur politische Bildung. 23.01. Доступ: https://www.bpb.de/internationales/europa/ukraine/284394/analyseleihmutterschaft-in-der-ukraine-aufstieg-und-fall-eines-lukrativen-internationalenmarktes (проверено 13.03.2020).

RUDAKOVA Ekaterina Konstantinovna, Cand.Sci. (Pol.Sci.), Senior Researcher, Associate Professor of the Chair of International Relations and Political Science, Dobroljubov State Linguistics University of Nizhny Novgorod(31a Minina St, Nizhny Novgorod, Russia, 603155; kafedra_mo_nglu@mail.ru)

SHUMAKOVA Olga Nikolaevna, Cand.Sci. (Philos.), Professor of the Chair of Philosophy and Aesthetics, Nizhny Novgorod State Glinka Conservatoire (40 Piskunova St, Nizhny Novgorod, Russia, 603950)

\section{LEGAL AND ETHICAL ISSUES OF THE USE OF AUXILIARY REPRODUCTIVE TECHNOLOGIES IN FOREIGN DISCOURSE IN THE CONTEXT OF DEMOGRAPHIC SECURITY OF RUSSIA}

Abstract. The article discusses foreign discourse regarding the legal, ethical, social and demographic consequences of the use of new medical technologies in the reproductive sphere in the context of ensuring the demographic security of the state. The authors conclude that Russian legislation requires legislative restrictions on certain types of reproductive technologies that are contrary to international and national law and threaten the mental and physical health of future generations. The study shows that in most western countries, new reproductive technologies, such as surrogate motherhood, egg donation, in vitro fertilization, had already received significant legislative restrictions due to little knowledge of the effects of these technologies on the health of mothers and children, as well as to ethical and religious traditions in the society.

Keywords: demographic security, assisted reproductive technologies, in vitro fertilization, surrogacy, ethics, morality, human rights 